\title{
Standing on the shoulders of giants
}

\author{
Nature Photonics pays tribute to the pioneering scientists that helped define the field of photonics in the latter part \\ of the twentieth century with the launch of an online collection of profiles.
}

T his month, to celebrate the 2019 International Day of Light that takes place on 16 May, we have decided to launch an online collection entitled 'Pioneers of Photonics' (https://www.nature, com/collections/ihjhdhcijj/). This unique collection brings together in one place all the obituaries that we have published in Nature Photonics since our launch in 2007.

Numerous scientists who have proved to be highly influential and a great source of inspiration for the photonics community, since the invention of the laser in 1960 , are profiled and celebrated. The idea is to tell the life stories of these great researchers, to provide the context and history behind their scientific achievements, and to explain how their activities changed the field of optics.

It should be noted that this is not, and does not intend to be, a comprehensive collection. Only those who have passed away since Nature Photonics came into existence and whose contributions have received widespread international recognition are included.

The collection launches with a total of nine profiles, including of five Nobel laureates: Charles Townes (accredited as one of the inventors of the laser); Nicolaas Bloembergen (a pioneer of nonlinear optics); Emil Wolf (who developed optical coherence theory); Osamu Shimomura (who isolated green fluorescent protein from jellyfish); Charles Kao (who inspired silica glass optical fibre communications); Victor Veselago (who investigated the notion of a material with a negative refractive index); John Love (an expert in waveguide theory); Ronald Drever (whose ideas on laser stabilization were crucial to gravitationalwave detection); and Roy Glauber (who developed the quantum theory of optical coherence).

The intention is to add to the collection so that it grows over time, and currently

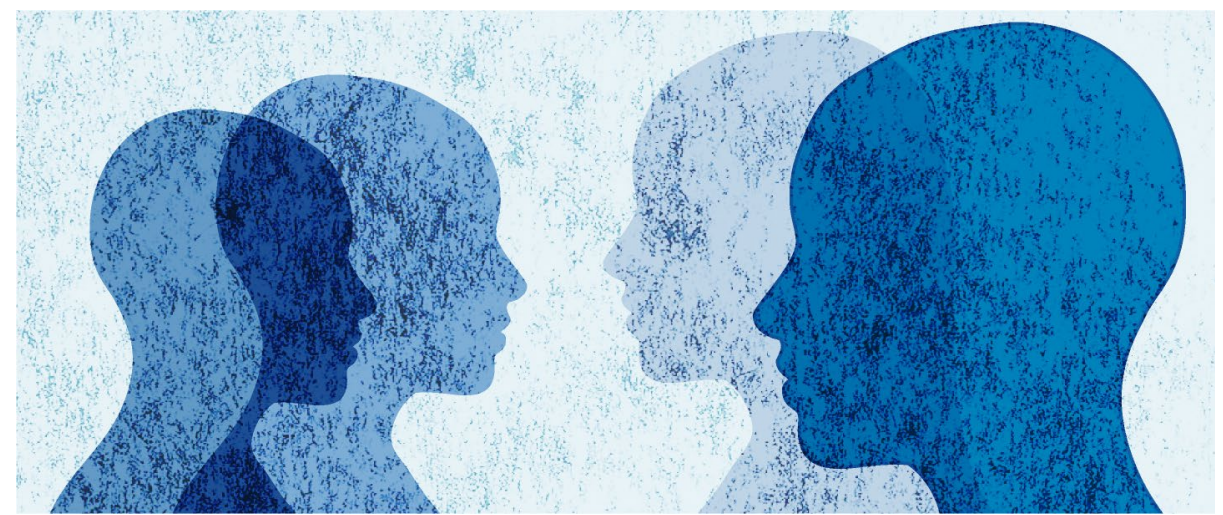

a number of additional profiles are under preparation.

Several points have come across clearly while preparing this collection. The first is that all these great scientists lived through the Second World War and many were caught up in its consequences during the early stages of their careers. For example, Shimomura was near Nagasaki when the atomic bomb exploded in August 1945, Bloembergen was studying in Holland during the repressive conditions of the German occupation, and Glauber worked on the Manhattan Project at the Los Alamos National Laboratory. Yet despite considerable hardship and difficulties at times, they all persevered and were highly successful.

Another point is that many of these scientists were not just great researchers but also great educators and were passionate about giving back to the community. Several have authored hugely influential and popular textbooks - for example, Max Born's and Wolf's Principles of Optics that was first published in 1959 and has since been revised a further six times is a wellknown classic. It has been described as "probably the most influential book in optics published in the past 40 years." Love's Optical Waveguide Theory, which was co-authored with Allan Synder and published in 1983, is a much revered reference among those working in integrated optics and fibre optics. Finally, Shimomura's Bioluminescence: Chemical Principles and Methods published in 2006 is known colloquially as the "bible of bioluminescence".

Many also shared a great sense of humour and humility. Glauber famously was the 'keeper of the broom' during the Ig Nobel Prize ceremonies, where he would zealously sweep up all the paper aeroplanes thrown by the attendees. While Bloembergen told his students that he was simply "in the right place at the right time" when quizzed about his Nobel Prize.

As we celebrate the 2019 International Day of Light we feel that it is a timely opportunity to remind all those working in photonics today that we are all "standing on the shoulders of giants" (as Isaac Newton allegedly once said to Robert Hooke in a letter in 1676). These giants deserve to be remembered and celebrated. We hope you enjoy the collection and would like to thank all the contributors that have made it possible.

Published online: 24 April 2019 https://doi.org/10.1038/s41566-019-0438-y 